\title{
Molecular Docking Analysis of Chlorogenic Acid Against Matrix Metalloproteinases (MMPs)
}

\author{
Dhivyadharshini Govindharaj 1(D), Saraswathy Nachimuthu ${ }^{1 * \mathbb{D}}$, Dymphan F Gonsalves ${ }^{1(D)}$, Ram \\ Kothandan $^{1}{ }^{(1)}$, Bhaarathi Dhurai ${ }^{2}$ (D), Lakshminarayanan Rajamani ${ }^{3}$ (D), Seeram Ramakrishana ${ }^{4}$ \\ 1 Department of Biotechnology, Kumaraguru College of Technology, Coimbatore, 641049; \\ dhivyadharshini.18mbt@kct.ac.in; saraswathy.n.bt@kct.ac.in; dymphan.17phd@kct.ac.in; ram.k.bt@kct.ac.in; \\ 2 Department of Fashion Technology, Kumaraguru College of Technology, Coimbatore -641049; \\ bhaarathidhurai.txt@kct.ac.in; \\ 3 Anti-infective Research Group, Singapore Eye Research Institute (SERI), Singapore 169856; \\ lakshminarayanan.rajamani@seri.com.sg; \\ 4 Centre for Nanofibre and Technology, Faculty of Engineering, National University of Singapore (NUS), Singapore; \\ seeram@nus.edu.sg; \\ * Correspondence: saraswathy.n.bt@kct.ac.in;
}

Received: 10.05.2020; Revised: 28.05.2020; Accepted: 30.05.2020; Published: 31.05.2020

Abstract: Wound healing is one of the most critical and complex processes in the human system, which involves many enzymes. Overexpression of Matrix metalloproteinases (MMPs) at the wound site delay the wound healing process. These overexpressed MMPs can be down-regulated or inhibited using small bioactive molecules derived from natural sources. Chlorogenic acid is a polyphenol derivative found in coffee and a well-known antioxidant. The main objective of the study is to unveil the molecular mechanism by which chlorogenic acid binds to the MMPs through molecular docking studies. The result of docking studies showed that chlorogenic acid showed an excellent binding affinity towards all four selected MMPs. The free binding energy of MMPs 2, 3, 8, and 12 were about -9.32, -8.17, -8.85, and $-7.431 \mathrm{kcal} / \mathrm{mol}$, respectively. Thus, chlorogenic acid can be used to regulate the activity of metalloproteinases and help to promote wound healing activity.

Keywords: Chlorogenic acid, Matrix metalloproteinases, Antioxidant, Molecular Docking.

(C) 2020 by the authors. This article is an open-access article distributed under the terms and conditions of the Creative Commons Attribution (CC BY) license (https://creativecommons.org/licenses/by/4.0/).

\section{Introduction}

Skin is the largest and essential part of the body that protects the body from invasion of microorganisms [1,2]. The normal healthy skin is remarkably intact and can control the entry and growth of microbes [3, 4]. Any damage in the skin that causes the loss of integrity of the skin is termed as wound. Generally, a wound is a regular event in every individual's life [5]. There are a series of events that help in wound healing [6]. The four events of wound healing are hemostasis, inflammation, proliferation, and tissue remodeling [7, 8]

The wound site consists of various enzymes that modulate the wound healing process [9]. Enzymes that are present in the extracellular matrix (ECM) are called matrix metalloproteinases (MMPs), also known as matrixins [10,11]. MMPs belong to endoproteases that depend on zinc for their activity [12, 13]. There are about 23 MMPs in human beings, which are divided into six classes [14]. Gelatinase (MMP2), stromelysins (MMP3), collagenase (MMP8), and metalloelastase (MMP12) are few MMPs that are mainly involved in tissue repairing process $[15,16]$. Under normal condition, MMPs are secreted in a balanced manner, 
but due to oxidative stress in the wound site, there is an improper regulation in MMPs and endogenous regulatory process, which leads to degradation of newly formed ECM by MMPs, thus delaying the wound healing process and leading to chronic wound infections [17].

Many medicinal plants have been reported to possess compounds that are showing significant wound healing activity [18], which posses less or no side effects compared to synthetic compounds [19]. Chlorogenic acid (CGA) is a secondary metabolite belongs to a group of phenolic compounds [20], and it is majorly present in plants such as coffee, vegetables such as potatoes and fruits including apples, pears, berries, etc., [21, 22]. It is known show free radical and metal scavenging activities [23, 24]. IUPAC chemical name of CGA is called 1,3,4,5-tetrahydroxy cyclohexane carboxylic acid 3-(3,4-dihydroxycinnamate) $[25,26]$. It is known to show that CGA possesses antioxidant, anticarcinogenesis, hepato-protectant $[27,28]$ and also plays a significant role in the wound healing process [29]. CGA is helpful in the wound healing process by increasing hydroxyproline content, diminishing nitric oxide levels, and also promotes reduced-glutathione levels in wound bed [30].

Molecular docking is the in silico approach where the protein and ligand are used to find the best interactions between them. Hence, the results from in silico studies could be used to find the relevant information before in vitro and in vivo studies. This study is to understand of the interaction of CGA with and MMPs that are involved in the wound healing process.

\section{Materials and Methods}

\subsection{Protein preparation.}

The three-dimensional structure of the selected matrix metalloproteinases (MMPs) were retrieved from RCSB database (https://www.rcsb.org/) in Protein Data Bank (PDB) format. The four selected MMPs are of Homo sapiens origin, and PDB code of MMP 2, MMP 3, MMP 8 and MMP 12 is $1 \mathrm{QIB}, 2 \mathrm{DIO}, 1 \mathrm{MNC}$, and 1HNE, respectively [16].

\subsection{Ligand preparation.}

The three-dimensional structure of the CGA was retrieved from the PubChem database (https://pubchem.ncbi.nlm.nih.gov/). The compound ID of CGA is 1794427 with the molecular formula of $\mathrm{C}_{16} \mathrm{H}_{18} \mathrm{O} 9$, and the molecular weight is $354.31 \mathrm{~g} / \mathrm{mol}$. The CGA was screened by using an online server http://www.scfbio-iitd.res.in/software/drugdesign/lipinski.jsp in order to find its physicochemical properties such as molecular weight, hydrogen bond donors, hydrogen bond acceptors, lipophilicity and molar refractivity [31,32] and its properties were compared with Lipinski's rule of five [33, 34].

\subsection{Active sites of MMPs.}

The active site is one of the essential criteria in docking studies where the ligand interacts with the protein's active site amino acid residues to give effective binding interactions. In the present study, the experimentally verified active site residues of the selected MMPs, MMP2, MMP 3, MMP8, and MMP12 were considered based on literature reports [35-38].

\subsection{Dock preparation.}

The retrieved MMPs were processed using USFC Chimera 1.31.1. The additional chains present in the protein structure were removed, and only one chain was used. During dock preparation, ions, ligands, and water molecules present in each protein crystal structure 
were removed. Then, the charges were added additionally to other residues (Gasteiger) and standard residues (AMBERff14SB). These dock prepared proteins were used for further docking process. Similarly, the CGA structure was also dock prepared using USFC Chimera 1.31.1 [39, 40].

\subsection{Molecular docking process.}

AutoDock tool 1.5.6 was used for analyzing the docking studies between MMPs and CGA. The dock prepared MMPs and CGA were reconstructed into PDBQT format. For CGA, a torsion tree was applied to rotate all the rotatable bonds. The original grid spacing of 0.375 $\AA$ Á was remodeled according to the active site residues and fitted into the active site cavity of the protein molecules. The chlorogenic acid was docked against all the four selected MMPs; MMP2, MMP 3, MMP8, and MMP12 separately. Here, Lamarckian genetic algorithm (LGA) was used, and the population size was about 150, the maximum number of generations was about 27000. The rate of gene mutation and crossover was set about 0.02 and 0.8 , respectively [41]. Based on the RMSD and affinity score, out of 10 conformations, one of the best docking pose for each MMP was taken for further analysis. The resulting best conformation of CGA and MMP was visualized using USFC Chimera 1.31.1. The hydrogen bonds between active site residues of MMP and CGA were also noted for interaction analysis [42, 43].

\section{Results and Discussion}

\subsection{Protein and ligand preparation.}

MMPs are a group of enzymes involved in the wound healing process, and four MMPs such as MMP2, MMP3, MMP8, and MMP12 were selected for the docking study. Under natural conditions, these MMPs are regulated in a balanced manner, but under certain conditions like a chronic wound, these MMPs activity is upregulated, and it leads to delay in wound healing $[44,45]$. CGA is a natural bioactive compound found in coffee was selected as a ligand to study the interaction with the selected MMPs [46]. The 3D structure of selected MMPs was retrieved from RCSB in PDB format, and CGA structure was obtained from PubChem database are shown in Figures 1 and 2. Selected MMPs and CGA were docks prepared using chimera software before subjecting to the docking process. The dock preparation includes removal of ions, ligands, the addition of hydrogen bonds, and also the addition of Gasteiger charges.

\subsection{Ligand properties.}

The ligand properties of CGA were predicted using the Lipinski rule of five, and the detail is shown in table 1. The results showed that CGA follows all the five rules except one property. The number of hydrogen donors for CGA was found to be six whereas it is expected less than five. However, Lipinski's rule of five does not apply to natural compounds [47].

\subsection{Active site prediction of MMPs.}

The amino acid residues present in the active site of selected MMPs, MMP2, MMP3, MMP8, and MMP12, are listed in table 2. Phe, Asn, Tyr, Asp, His, Ser, Val, Glu, etc., were some of the active site residues. These residues show stronger binding interaction with the ligand molecule. 


\subsection{Docking interaction and analysis.}

The docking studies were done using AutoDock Tool 1.5.6. The dock prepared CGA was docked with all four selected dock prepared MMPs. The best interactions between MMPs and CGA were predicted using the Root Mean Square Deviation (RMSD) score and binding affinity values. The selected best poses were analyzed for hydrogen bond donor residues and also the relative bond distances between the MMPs active sites and CGA.

\subsubsection{Interaction between CGA and MMP 2.}

The molecular interaction between MMP2 and CGA was visualized using chimera software is shown in figure $3 \mathrm{a}$. From figure $3 \mathrm{a}$, it was found that CGA fits into the active site pocket, and it interacts with amino acid residues of MMP 2 that is likely to show more excellent inhibition activity in under in vivo condition. CGA interaction with MMP 2 (Gelatinase) showed the second-highest affinity score of about $-9.32 \mathrm{kcal} / \mathrm{mol}$ out of 10 poses and RMSD score 72.55 . The bond length and hydrogen bonding residues are listed in table 3 . Thus, CGA could help in regulating the enzyme gelatinase and thereby enhancing the amount of gelatin, collagen, elastin, and fibronectin in the wound site and decreasing the aggregation of platelets, pro-inflammatory factors and also reducing proteolytic affect at the wound site thereby faster ECM development and helps in the wound healing process [16, 48].

\subsubsection{Interaction between CGA and MMP 3.}

MMP3 belongs to stromelysins subfamily, and it enhances the production of laminin, aggregan, gelatin, and fibronectin in wound site, which leads to a faster wound healing process. The hydrogen bonding that is formed between active site residues of MMP 3 and CGA was visualized using chimera and shown in figure $3 \mathrm{~b}$. The bond length and hydrogen bonding residues are given in table 3 . It showed the interactions score between MMP3 and CGA of about - $-8.17 \mathrm{kcal} / \mathrm{mol}$ out of 10 poses and RMSD scores 93 . Figure $3 \mathrm{~b}$ indicates that CGA fits into the active site pocket of MMP 3 and forms hydrogen bonds with interacting amino acid residues. Hence CGA can be considered as a potential inhibitor molecule. It can down-regulate the MMP 3 (stromelysins) activity and which in turn reduces the activity of TGF- $\beta$ and anti-inflammatory factors at the wound site [27].

\subsubsection{Interaction between CGA and MMP 8}

MMP 8 belongs to the collagenase 2 subfamily, which is involved in the degradation of collagen deposition in the extracellular matrix [49]. Excess degradation of collagen type I results in a decrease in wound healing. Therefore, inhibiting the activity of MMP 8 at the wound site is essential to enhance the collagen deposition [50]. Interaction between MMP8 and CGA through hydrogen bonding was visualized using chimera is shown in figure 3c. From figure 3c, it was found that CGA fits into the active site pocket, and out of four MMPs selected, MMP 8 showed maximum affinity score of about $8.85 \mathrm{kcal} / \mathrm{mol}$ out of 10 poses and RMSD score was found to be 34.03 . Hence, CGA may provide more excellent inhibitor activity towards the MMP 8 . The bond length and hydrogen bonding residues were listed in table 3. Regulating the collagenase at the wound site can help to decrease the degradation of collagen at the wound site, and increase the accumulation of gelatin, aggrecan, fibronectin synthesis. Inactivation of MMP 8 leads to lowering the activity of chemokines and cell migration towards the wound site, which leads to reducing the inflammatory activity and promoting the wound healing process [51].

\subsubsection{Interaction between CGA and MMP 12}

MMP 12 belongs to metalloelastase group of enzymes, which are essential for tissue repairing process. But overexpression of MMP 12 results in infiltration of inflammatory cells and delays wound healing [52]. Docking between CGA and MMP12 showed that CGA fit into the active site of the MMP 
12 , and the interaction was visualized using chimera and represented in figure $3 \mathrm{~d}$. Hydrogen bond length and hydrogen bonding residues in the active site of MMP12 are listed in table 3. From the figure $3 \mathrm{~d}$, it was found that CGA fits to the active site pocket of MMP12 with affinity score of binding was estimated to $-7.43 \mathrm{kcal} / \mathrm{mol}$ out of 10 poses and RMSD score of about 64.84 . The inhibitory nature of CGA under in vivo condition will help in reducing the activity of MMP12 activity at the wound site and enhance the accumulation of elastin, gelatin, collagen, fibronectin, laminin, vitronectin, proteoglycan, and angiogenesis help in faster wound healing process [53].<smiles>O=C(/C=C/c1ccc(O)c(O)c1)O[C@@H]1C[C@](O)(C(=O)O)C[C@H](O)[C@H]1O</smiles>

Figure 1. Structure of Chlorogenic acid.

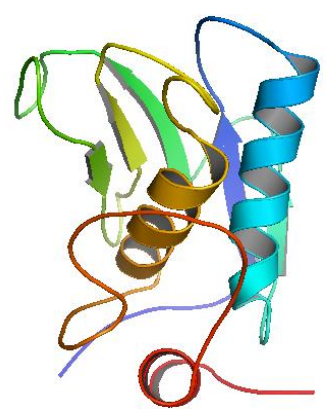

(a)

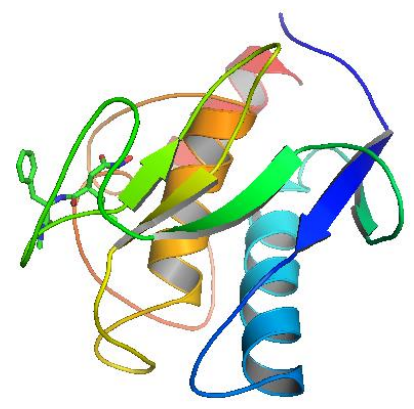

(c)

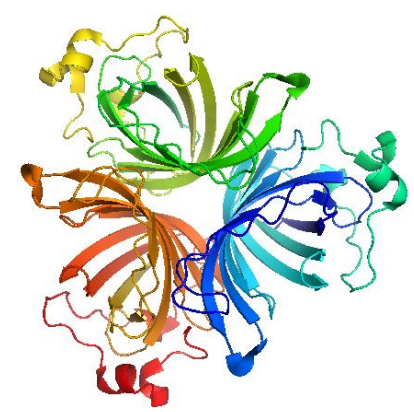

(b)

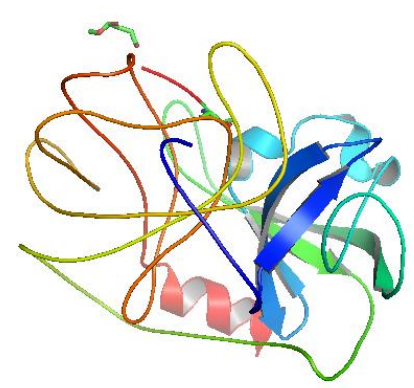

(d)

Figure 2. Structure of Matrix Metelloproteinases (MMPs) (a)MMP2, (b)MMP3, (c)MMP8 and (d)MMP12.

Table 1. Lipinski rule of Five.

\begin{tabular}{l|l|l} 
Lipinski rule & Accepted values & Value for Chlorogenic acid \\
\hline Molecular mass(Da) & $<500$ & 354.0 \\
\hline Hydrogen bond donor & $<5$ & 6 \\
\hline Hydrogen bond acceptors & $<10$ & 9 \\
\hline High lipophilicity (LOGP) & $<5$ & -0.6459 \\
\hline Molar refractivity & $40-130$ & 82.518768
\end{tabular}

Table 2. Active site residues present in selected MMPs.

\begin{tabular}{|c|c|c|c|}
\hline Enzymes & Residues in the active site & Amino acids & Reference \\
\hline MMP2 & $\begin{array}{l}162,163,164,165,201,202, \\
221,222,223\end{array}$ & $\begin{array}{l}\text { Asn, Val, Leu, Ala, His, Glu, Pro, } \\
\text { Leu, Tyr }\end{array}$ & {$[35]$} \\
\hline MMP3 & $\begin{array}{l}23,25,31,43,49,51,53,71,85, \\
89,105,136\end{array}$ & $\begin{array}{l}\text { Glu, Asn, Ser, Phe, Val, Phe, Cys, } \\
\text { Phe, Tyr, Tyr, Tyr }\end{array}$ & {$[36]$} \\
\hline MMP8 & $179,181,182,219,238,240$ & Gly, Leu, Ala, Glu, Pro, Tyr & [37] \\
\hline MMP12 & $\begin{array}{l}57,102,192,193,194,195,213, \\
214,215,216,226\end{array}$ & $\begin{array}{l}\text { His, Asp, Phe, Gly, Asp, Ser, Ala, } \\
\text { Ser, Phe, Val, Asp }\end{array}$ & [38] \\
\hline
\end{tabular}




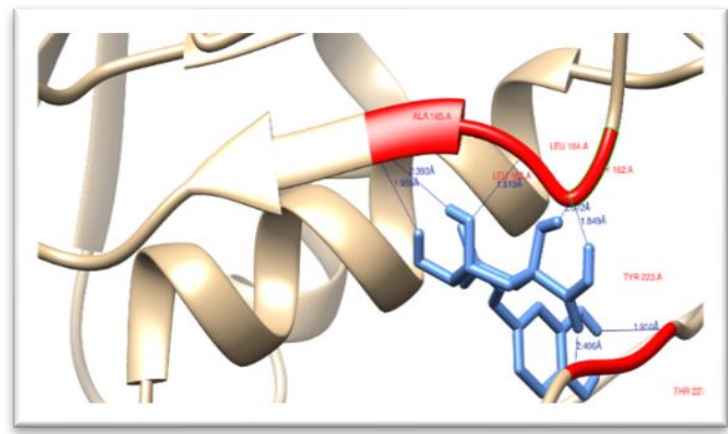

(a)

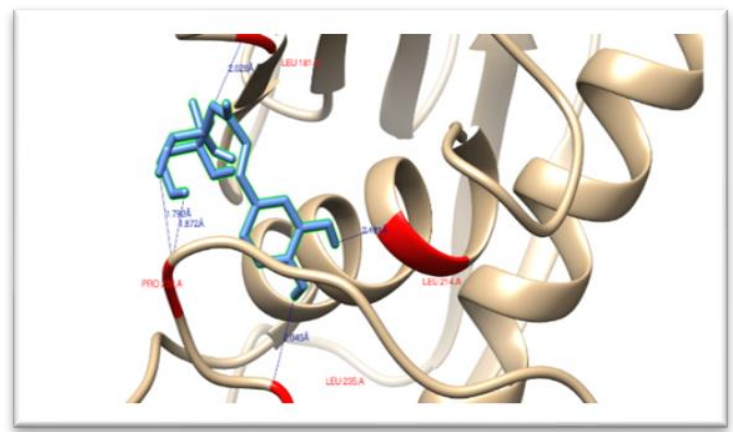

(c)

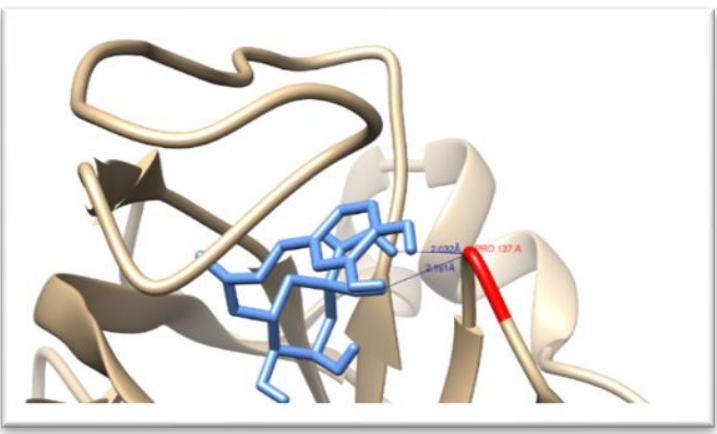

(b)

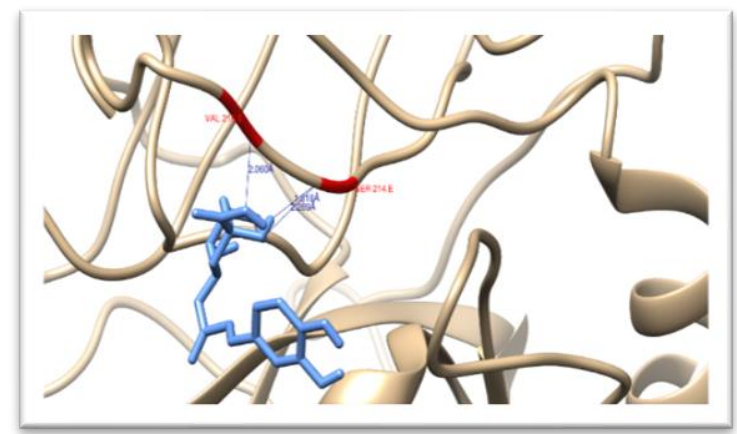

(d)

Figure 3. Hydrogen bonding interaction of CGA in the active site of MMPs (a) MMP2 (b) MMP3 (c) MMP8 (d) MMP12

Table 3. Molecular interactions observed between CGA and selected MMPs.

\begin{tabular}{|c|c|c|c|c|c|c|c|c|}
\hline $\begin{array}{l}\text { Receptor } \\
\text { protein }\end{array}$ & $\begin{array}{l}\text { No. of } \\
\text { H } \\
\text { bonds } \\
\text { present }\end{array}$ & $\begin{array}{l}\text { Amino } \\
\text { acid } \\
\text { residues } \\
\text { that } \\
\text { forms } \\
\text { H bond } \\
\end{array}$ & $\begin{array}{l}\text { Length } \\
\text { of H- } \\
\text { bond (Á) }\end{array}$ & $\begin{array}{l}\text { Binding } \\
\text { energy } \\
(\mathrm{kcal} / \mathrm{mol})\end{array}$ & $\begin{array}{l}\text { Inhibitor } \\
\text { constant ki } \\
\text { (micromolar) } \\
\text { at } \\
\text { temperature } \\
298.15 \mathrm{~K} \\
\end{array}$ & $\begin{array}{l}\text { Final } \\
\text { intermolecular } \\
\text { energy } \\
\text { (kcal/mol) }\end{array}$ & $\begin{array}{l}\text { Reference } \\
\text { RMSD }\end{array}$ & $\begin{array}{l}\text { Cluster } \\
\text { RMSD }\end{array}$ \\
\hline MMP2 & 6 & $\begin{array}{l}\text { Gly } 162 \\
\text { Leu } 164 \\
\text { Ala } 165 \\
\text { Try } 223 \\
\end{array}$ & $\begin{array}{l}1.849 \\
2.072 \\
1.819 \\
1.959 \\
2.939 \\
2.406 \\
\end{array}$ & -9.32 & 1.50 & -11.61 & 72.55 & 0 \\
\hline MMP3 & 2 & Pro 137 & $\begin{array}{l}2.032 \\
2.191 \\
\end{array}$ & -8.17 & 5.56 & -10.45 & 93 & 0 \\
\hline MMP8 & 2 & $\begin{array}{l}\text { Leu } 181 \\
\text { Pro } 238\end{array}$ & $\begin{array}{l}2.028 \\
1.792 \\
1.872 \\
\end{array}$ & -8.85 & 51.82 & -9.13 & 34.03 & 0 \\
\hline MMP12 & 2 & $\begin{array}{l}\text { Ser } 214 \\
\text { Val } 216\end{array}$ & $\begin{array}{l}1.818 \\
2.269 \\
2.060\end{array}$ & -7.43 & 710.69 & -7.58 & 64.84 & 0 \\
\hline
\end{tabular}

\section{Conclusions}

The molecular docking studies between CGA and MMPs revealed that CGA is a potential inhibitory molecule. From the interaction results, it is observed that CGA fits into the active site of MMPs and also interacts with active site amino acid residues present in the MMPs through hydrogen bonding. It is also shown that CGA showed an affinity towards all four MMPs. Further, in vivo studies to be carried out to evaluate the inhibitory potential of CGA to 
down-regulate excess activity of selected the MMPs in the chronic wound site to promote the faster wound healing process.

\section{Funding}

This research was funded by MHRD, Government of India, under the SPARC scheme (SPARC/2018-2019/141/SL(IN) dated $18^{\text {th }}$ March 2019).

\section{Acknowledgments}

This research has no acknowledgment.

\section{Conflicts of Interest}

The authors declare no conflict of interest.

\section{References}

1. Yousef, H.; Alhajj, M.; Sharma, S. Anatomy, skin (integument). Epidermis 2019. Treasure Island (FL): StatPearls Publishing, https://www.ncbi.nlm.nih.gov/books/NBK470464/

2. Polańska, A.; Cieplewicz, P.; Adamski, Z.; Żaba, R.; Dańczak-Pazdrowska, A. The influence of ultraviolet radiation on the aging process of the skin. Journal of Face Aesthetics 2019, 2, 28-37, https://doi.org/10.20883/jofa.8.

3. Mir, M.; Ali, M.N.; Barakullah, A.; Gulzar, A.; Arshad, M.; Fatima, S.; Asad, M. Synthetic polymeric biomaterials for wound healing: a review. Progress in Biomaterials 2018, 7, 1-21, https://doi.org/10.1007/s40204-018-0083-4.

4. Grada, A.; Obagi, Z.; Phillips, T. Management of chronic wounds in patients with pemphigus. Chronic Wound Care Management and Research 2019, 6, 89, https://doi.org/10.2147/CWCMR.S141948.

5. Price, A.; Naik, G.; Harding, K. Skin repair technology. In: Biomaterials for Skin Repair and Regeneration. Woodhead Publishing. 2019; 27-57, https://doi.org/10.1016/B978-0-08-102546-8.00002-9.

6. Perchyonok, V.T. Copazan herbal gel and wound healing in vitro: Assessment of the functional biomaterial for veterinary application. Biointerface Research in Applied Chemistry 2018, 8, 3084-3088.

7. Bhatt, T.; Kansagar, G.; Pincha, N.; Jamora, C. How does the skin heal wounds? Iwonder 2019, 3, 13-18. http://publications.azimpremjifoundation.org/id/eprint/2092

8. Gonzalez, A.C.d.O.; Costa, T.F.; Andrade, Z.d.A.; Medrado, A.R.A.P. Wound healing - A literature review. Anais Brasileiros de Dermatologia 2016, 91, 614-620, http://dx.doi.org/10.1590/abd1806-4841.20164741.

9. De Sousa, F.; Rogênio, F.; Mendes, F.; Bermudez, J.; Brandão da Silva, A.; Da, M.; Vasconcelos, M.; Lourenzoni, M.; Oliveira Filho, R.; Campos, A.; De, R.; Moreira, A.; Cristina, A.; Monteiro-Moreira, O. Plant Macromolecules as Biomaterials for Wound Healing. 2019; In: Wound Healing. IntechOpen 2019; 21, https://doi.org/10.5772/intechopen.89105.

10. Nguyen, T.T.; Mobashery, S.; Chang, M. Roles of matrix metalloproteinases in cutaneous wound healing. Wound Healing - New insights into Ancient Challenges 2016, 37-71, http://dx.doi.org/10.5772/64611.

11. Rousselle, P.; Montmasson, M.; Garnier, C. Extracellular matrix contribution to skin wound reepithelialization. Matrix Biology 2019, 75-76, 12-26, https://doi.org/10.1016/j.matbio.2018.01.002.

12. Krejner, A.; Litwiniuk, M.; Grzela, T. Matrix metalloproteinases in the wound microenvironment: therapeutic perspectives. Chronic Wound Care Management and Research 2016, 23, 29-39, https://doi.org/10.2147/CWCMR.S73819.

13. Ibrahim, W.; Syaiful, M.; Doolaanea, A.A. Matrix Metalloproteinases In Cancer Biology: A Review. International Medical Journal Malaysia $\quad 2019, \quad 18, \quad 147-152$. https://journals.iium.edu.my/kom/index.php/imjm/article/view/75

14. Jabłońska-Trypuć, A.; Matejczyk, M.; Rosochacki, S. Matrix metalloproteinases (MMPs), the main extracellular matrix (ECM) enzymes in collagen degradation, as a target for anticancer drugs. Journal of Enzyme Inhibition and Medicinal Chemistry 2016, 31, 177-183, https://doi.org/10.3109/14756366.2016.1161620.

15. Li, K.; Tay, F.R.; Yiu, C.K.Y. The past, present and future perspectives of matrix metalloproteinase inhibitors. Pharmacology \& Therapeutics 2020, 207, https://doi.org/10.1016/j.pharmthera.2019.107465.

16. Selvaraj, G.; Kaliamurthi, S.; Thiruganasambandam, R. Molecular docking studies of rutin on matrix metalloproteinase. Insights Biomed 2016, 1(1). 
17. Lallemand, L.A.; Zubieta, C.; Lee, S.G.; Wang, Y.; Acajjaoui, S.; Timmins, J.; McSweeney, S.; Jez, J.M.; McCarthy, J.G.; McCarthy, A.A. A Structural Basis for the Biosynthesis of the Major Chlorogenic Acids Found in Coffee. Plant Physiology 2012, 160, 249-260, https://doi.org/10.1104/pp.112.202051.

18. Ibrahim, N.; Wong, K.S.; Mohamed, N.I.; Mohamed, N.; Chin, K.-Y.; Ima-Nirwana, S.; Shuid, N.A. Wound Healing Properties of Selected Natural Products. International Journal of Environmental Research and Public Health 2018, 15, https://doi.org/10.3390/ijerph15112360.

19. Hassan, A., Ullah, H. IsrarMatejczyk, M., The antioxidant activity and phytochemical analysis of medicinal plant Veronica biloba. Letter in applied nanaoscience. $2019 . \quad 8 \quad$ (4), $732 \quad$ - 738. https://doi.org/10.33263/LIANBS84.732738

20. Matejczyk, M.; Ofman, P.; Dąbrowska, K.; Świsłocka, R.; Lewandowski, W. The study of biological activity of transformation products of diclofenac and its interaction with chlorogenic acid. Journal of Environmental Sciences 2020, 91, 128-141,. https://doi.org/10.1016/j.jes.2020.01.022.

21. Bagdas, D.; Gul, N.Y.; Topal, A.; Tas, S.; Ozyigit, M.O.; Cinkilic, N.; Gul, Z.; Etoz, B.C.; Ziyanok, S.; Inan, S.; Turacozen, O.; Gurun, M.S. Pharmacologic overview of systemic chlorogenic acid therapy on experimental wound healing. Naunyn-Schmiedeberg's Archives of Pharmacology 2014, 387, 1101-1116, https://doi.org/10.1007/s00210-014-1034-9.

22. Park, J.J.; Hwang, S.J.; Park, J.-H.; Lee, H.-J. Chlorogenic acid inhibits hypoxia-induced angiogenesis via

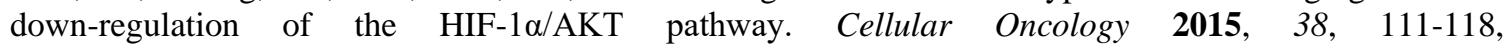
https://doi.org/10.1007/s13402-014-0216-2.

23. Kim, J.; Jeong, I.-H.; Kim, C.-S.; Lee, Y.M.; Kim, J.M.; Kim, J.S. Chlorogenic acid inhibits the formation of advanced glycation end products and associated protein cross-linking. Archives of Pharmacal Research 2011, 34, 495-500, https://doi.org/10.1007/s12272-011-0319-5.

24. Holopainen, J.M.; Moilanen, J.A.O.; Sorsa, T.; Kivelä-Rajamäki, M.; Tervahartiala, T.; Vesaluoma, M.H.; Tervo, T.M.T. Activation of Matrix Metalloproteinase-8 by Membrane Type 1-MMP and Their Expression in Human Tears after Photorefractive Keratectomy. Investigative Ophthalmology \& Visual Science 2003, 44, 2550-2556, https://doi.org/10.1167/iovs.02-1190.

25. Kim, J.K.; Park, S.U. Chlorogenic acid and its role in biological functions: an up to date. EXCLI journal 2019, 18, 310-316, http://dx.doi.org/10.17179/excli2019-1404.

26. Cho, H J.; Kang, H.J.; Kim, Y.J.; Lee, D.H.; Kwon, H.W.; Kim, Y.Y.; Park, H.J. Inhibition of platelet aggregation by chlorogenic acid via cAMP and cGMP-dependent manner. Blood Coagul. Fibrinolysis 2012, 23, 629-635. https://doi.org/10.1097/MBC.0b013e3283570846.

27. Chen, W.C.; Liou, S.S.; Tzeng, T.F.; Lee, S.L.; Liu, I.M. Effect of Topical Application of Chlorogenic Acid on Excision Wound Healing in Rats. Planta Med 2013, 79, 616-621.

28. De Camargo, A.C.; Lima, R.S. A perspective on phenolic compounds, their potential health benefits, and international regulations: The revised Brazilian normative on food supplements. Journal of Food Bioactives 2019, 7, https://doi.org/10.31665/JFB.2019.7193.

29. Ave, O.R. Exploring the Potential of Green Coffee Extract for Wound Healing Treatment. IOP Conference Series: Earth and Environmental Science 2019, 391, 012057. IOP Publishing.

30. Bagdas, D.; Etoz, B.C.; Gul, Z.; Ziyanok, S.; Inan, S.; Turacozen, O.; Gul, N.Y.; Topal, A.; Cinkilic, N.; Tas, S.; Ozyigit, M.O.; Gurun, M.S. In vivo systemic chlorogenic acid therapy under diabetic conditions: Wound healing effects and cytotoxicity/genotoxicity profile. Food and Chemical Toxicology 2015, 81, 5461, https://doi.org/10.1016/j.fct.2015.04.001

31. Lipinski, C.A. Lead- and drug-like compounds: the rule-of-five revolution. Drug Discovery Today: Technologies 2004, 1, 337-341, https://doi.org/10.1016/j.ddtec.2004.11.007.

32. Kataria, R.; Khatkar, A. In-silico design, synthesis, ADMET studies and biological evaluation of novel derivatives of Chlorogenic acid against Urease protein and H. Pylori bacterium. BMC Chemistry 2019, 13, https://doi.org/10.1186/s13065-019-0556-0.

33. Bare, Y.; Sari, D R.T.; Rachmad, Y.T.; Krisnamurti, G.C.; Elizabeth, A.; Maulidi, A. In Silico Insight the Prediction of Chlorogenic Acid in Coffee through Cyclooxygenase-2 (COX2) Interaction. Biogenesis: Jurnal Ilmiah Biologi 2019, 7, 100-105, https://doi.org/10.24252/bio.v7i2.9847.

34. Mohammadhassan, R., Fallahi, S., \& Mohammadalipour, Z. ADMET and pharmaceutical activity analysis of caffeic acid diversities by in silico tools. Letters in Applied NanoBioScience. 2020, 9, $840-848$. https://doi.org/10.33263/LIANBS91.840848

35. Dhanaraj, V.; Williams, M.G.; Ye, Q.; Pavlovsky, A.; Rubin, J.R.; Skeean, R.W. X-ray Structure of Gelatinase A Catalytic Domain Complexed with a Hydroxamate Inhibitor. Croatica chemica acta 1999, 72, 575-591.

36. Hofmann, E.; Zerbe, P.; Schaller, F. The Crystal Structure of \&lt;em\&gt;Arabidopsis thaliana\&lt;/em\&gt; Allene Oxide Cyclase: Insights into the Oxylipin Cyclization Reaction. The Plant Cell 2006, 18, 3201-3217, https://doi.org/10.1105/tpc.106.043984.

37. Koteswara Reddy, G.; Nagamalleswara Rao, K.; Yarrakula, K. Insights into structure and function of 30S Ribosomal Protein S2 (30S2) in Chlamydophila pneumoniae: A potent target of pneumonia. Computational Biology and Chemistry 2017, 66, 11-20, https://doi.org/10.1016/j.compbiolchem.2016.10.014. 
38. Navia, M.A.; McKeever, B.M.; Springer, J.P.; Lin, T.Y.; Williams, H.R.; Fluder, E.M.; Dorn, C.P.; Hoogsteen, K. Structure of human neutrophil elastase in complex with a peptide chloromethyl ketone inhibitor at 1.84-A resolution. Proceedings of the National Academy of Sciences 1989, 86, 7-11, https://doi.org/10.1073/pnas.86.1.7.

39. Kumar, G.; Patnaik, R. Inhibition of Gelatinases (MMP-2 and MMP-9) by Withania somnifera Phytochemicals Confers Neuroprotection in Stroke: An In Silico Analysis. Interdisciplinary Sciences: Computational Life Sciences 2018, 10, 722-733, https://doi.org/10.1007/s12539-017-0231-x.

40. Liang, P.; Zhang, Y.Y.; Yang, P.; Grond, S.; Zhang, Y.; Qian, Z.-J. Viridicatol and viridicatin isolated from a shark-gill-derived fungus Penicilliumpolonicum AP2T1 as MMP-2 and MMP-9 inhibitors in HT1080 cells by MAPKs signaling pathway and docking studies. Medicinal Chemistry Research 2019, 28, 1039-1048, https://doi.org/10.1007/s00044-019-02358-w.

41. Yadav, E.; Singh, D.; Debnath, B.; Rathee, P.; Yadav, P.; Verma, A. Molecular Docking and Cognitive Impairment Attenuating Effect of Phenolic Compound Rich Fraction of Trianthema portulacastrum in Scopolamine Induced Alzheimer's Disease Like Condition. Neurochemical Research 2019, 44, 1665-1677, https://doi.org/10.1007/s11064-019-02792-7.

42. Naeem, S.; Hylands, P.; Barlow, D. Docking Studies of Chlorogenic Acid against Aldose Redutcase by using Molgro Virtual Docker Software. JAPS 2013, 3, 13-20, https://doi.org/10.7324/JAPS.2013.30104.

43. Pathak, J.; Mondal, S.; Ahmed, H.; Rajneesh; Singh, S.P.; Sinha, R.P. In silico study on interaction between human polo-like kinase 1 and cyanobacterial sheath pigment scytonemin by molecular docking approach. Biointerface Research in Applied Chemistry 2019, 9, 4374-4378. https://doi.org/10.33263/BRIAC95.374378

44. Caley, M.P.; Martins, V.L.C.; O'Toole, E.A. Metalloproteinases and Wound Healing. Adv Wound Care (New Rochelle) 2015, 4, 225-234, https://doi.org/10.1089/wound.2014.0581.

45. Wlaschek, M.; Singh, K.; Sindrilaru, A.; Crisan, D.; Scharffetter-Kochanek, K. Iron and iron-dependent reactive oxygen species in the regulation of macrophages and fibroblasts in non-healing chronic wounds. Free Radical Biology and Medicine 2019, 133, 262-275, https://doi.org/10.1016/j.freeradbiomed.2018.09.036.

46. Zhou, L.; Ren, M.; Zeng, T.; Wang, W.; Wang, X.; Hu, M.; Su, S.; Sun, K.; Wang, C.; Liu, J.; Yang, C.; Yan, L. TET2-interacting long noncoding RNA promotes active DNA demethylation of the MMP-9 promoter in diabetic wound healing. Cell Death \& Disease 2019, 10, https://doi.org/10.1038/s41419-0192047-6.

47. Bickerton, G.R.; Paolini, G.V.; Besnard, J.; Muresan, S.; Hopkins, A.L. Quantifying the chemical beauty of drugs. Nature Chemistry 2012, 4, 90-98, https://doi.org/10.1038/nchem.1243.

48. Rodrigues, M.; Kosaric, N.; Bonham, C.A.; Gurtner, G.C. Wound Healing: A Cellular Perspective. Physiological Reviews 2018, 99, 665-706, https://doi.org/10.1152/physrev.00067.2017.

49. Kähäri, V.M.; Saarialho-Kere, U. Matrix metalloproteinases and their inhibitors in tumour growth and invasion. Ann Med. 1999, 31, 34-45, https://doi.org/10.3109/07853899909019260.

50. Danielsen, P.L.; Holst, A.V.; Maltesen, H.R.; Bassi, M.R.; Holst, P.J.; Heinemeier, K.M.; Olsen, J.; Danielsen, C.C.; Poulsen, S.S.; Jorgensen, L.N.; Ågren, M.S. Matrix metalloproteinase-8 overexpression prevents proper tissue repair. Surgery 2011, 150, 897-906, https://doi.org/10.1016/j.surg.2011.06.016.

51. Moghadam, E.S.; Ebrahimi, N.S.; Salehi, P.; Moridi Farimani, M.; Hamburger, M.; Jabbarzadeh, E. Wound Healing Potential of Chlorogenic Acid and Myricetin-3-O- $\beta$-Rhamnoside Isolated from Parrotia persica. Molecules 2017, 22, 1-15, https://doi.org/10.3390/molecules22091501.

52. Chan, M.F.; Li, J.; Bertrand, A.; Casbon, A.-J.; Lin, J.H.; Maltseva, I.; Werb, Z. Protective effects of matrix metalloproteinase-12 following corneal injury. Journal of Cell Science 2013, 126, 948-3960, https://doi.org/10.1242/jcs.128033.

53. Liang, N.; Kitts, D.D. Role of Chlorogenic Acids in Controlling Oxidative and Inflammatory Stress Conditions. Nutrients 2016, 8, 1-20, https://doi.org/10.3390/nu8010016. 